\title{
AGROINDÚSTRIA DE FRANGO BRASILEIRA: A IMPORTÂNCIA DO DESENVOLVIMENTO DE INDICADORES DE DESEMPENHO INSERIDOS NO CONCEITO DE GESTÃO DA CADEIA DE SUPRIMENTOS
}

\section{BRAZILIAN POULTRY AGROBUSINESS: THE IMPORTANCE OF BUILDING PERFORMANCE MEASURES RELATED TO THE CONCEPT OF SUPPLY CHAIN MANAGEMENT}

\author{
Frederico T.C. Sakamoto ${ }^{1}$; Antônio Cezar Bornia ${ }^{2}$ \\ SEARA Alimentos S.A. - Itajaí - Brasil - fsakamoto@seara.com.br \\ Universidade Federal de Santa Catarina - Florianópolis - Brasil - cezar@inf.ufsc.br \\ Recebido para publicação em: 22/04/05 \\ Aceito para publicação em: 02/09/05
}

\begin{abstract}
Resumo
$O$ artigo mostra porque o atual ambiente de mercado tem impelido as agroindústrias a buscarem formas de se manterem competitivas. Nestes últimos anos, a agroindústria de frango tem percebido que apesar do excelente desempenho no mercado global, há fatores preocupantes. A fim de continuar a apresentar os mesmos níveis de desempenho dos anos anteriores têm-se buscado sinergias na cadeia de suprimentos. Os indicadores de desempenho podem representar um papel importante nesta busca, sendo a escolha apropriada um desafio. Percebe-se através de exemplos como a tomada de decisão no intuito de melhorar um indicador de desempenho, sem o entendimento do conceito de gestão da cadeia se suprimentos, tende a refletir negativamente na cadeia do negócio.
\end{abstract}

Palavras chave: indicadores de desempenho; tomada de decisão; cadeia de suprimentos.

\section{Introdução}

O artigo mostra de maneira objetiva a atual situação da agroindústria brasileira de frango no mercado mundial. Apesar de uma história vitoriosa e de sucesso nestas últimas décadas, percebe-se que há fatores de mercado que sinalizam para a diminuição das margens operacionais de ganhos.

Achar sinergias na cadeia de suprimentos pode ser uma forma de se manter nos mesmos patamares de desempenho dos últimos anos. Descreve-se o macro processo de negócio da atividade agro-industrial, o qual é o foco de estudo.

Mostra-se de forma simples com uma decisão, com o intuito de diminuir custo em uma parte da cadeia, afeta os processos subseqüentes. Onde o efeito de diminuir custo inicialmente pretendido, quando analisado o impacto na cadeia, pode ser contrário, isto é, aumento de custo para o processo como um todo.

No processo de gestão, os indicadores de desempenho têm um papel fundamental. Como comentado por Beamon (1999) é um desafio selecionar indicadores de desempenho apropriados para analisar a cadeia de suprimentos, principalmente quando o processo enfocado é longo e complexo, como no caso da agroindústria de frango. 
O desafio é desenvolver sistemas de medidas que habilitem os gestores a ver as áreas onde as ações podem melhorar o ganho da cadeia de suprimentos como um todo, assim eles poderão focar suas atenções e obterem altos níveis de desempenho, como enfatizado por Lambert (2001), sendo este o cerne deste artigo.

\section{A importância dos indicadores de desempenho na cadeia}

A agroindústria de frango brasileira é um exemplo de competitividade no mercado mundial. Apesar do grande crescimento nesta última década em termos de volume produzido e vendido, existem fatores que a preocupam. No intuito se manter na frente de seus concorrentes mundiais, percebe-se que há necessidade de buscar formas de melhorar o desempenho das empresas que atuam neste segmento de indústria.

A gestão da cadeia de suprimentos é uma alternativa. Entende-se como gestão da cadeia de suprimentos a integração de processos de negócios chaves, desde os usuários finais, permeando fornecedores, a fim de prover produtos e informações de valor agregado para clientes e acionistas (LAMBERT, 2000). O motivo da integração, como colocado por Bowersox e Closs (1996, p.101), é o aumento da competitividade da cadeia, através de melhoramentos no processo logístico e redução de custo pela eliminação do desperdício e atividades duplicadas.

O papel dos indicadores de desempenho neste contexto é fundamental. É através deles que a empresa poderá verificar seu desempenho na cadeia de suprimentos. Segundo Fischmann e Zilber (1999, p.173), a empresa deve contar com um sistema de indicadores de desempenho que permita a verificação do efetivo sucesso de sua gestão estratégica, servindo de referencial para avaliação e realinhamento da empresa à missão, aos objetivos e às metas.

Apesar da importância dos indicadores de desempenho, é comum as empresa não terem respostas para questões simples como: "Quais são os indicadores de desempenho que irão representar melhor o desempenho, seja para a organização como um todo e para suas partes?" e "Quais são os padrões de desempenho apropriados e como podem ser agrupados para cada parte da organização?” (OTLEY, 1995, p.49).

Percebe-se assim a importância de estruturação dos indicadores estratégicos de desempenho para a agroindústria de frango no atual ambiente competitivo, onde a diminuição das margens operacionais, o poder de determinação do preço pelo mercado e a pressão contínua de melhora dos resultados fazem com que as empresas repensem seus modelos de acompanhamento da gestão.

\section{Foco nos custos no atual ambiente de mercado}

As empresas, para continuarem operando no mercado globalizado, necessitam ser competitivas, trazendo um retorno previamente estabelecido pelo seu dono, proprietários ou acionistas. Caso esta empresa não consiga atingir, em períodos consecutivos, o resultado desejado e retornos preestabelecidos, os investimentos diminuem, as atividades permanecem estabilizadas e em determinados casos, o negócio é vendido ou fechado.

A equação a seguir, adaptada de Bornia (2002, p.60), procura descrever de forma simples o raciocínio utilizado pelos gestores das empresas modernas para a manutenção do lucro: $\mathrm{C}=\mathrm{P}-\mathrm{L}$. Onde $\mathrm{C}$ é o custo despendido na cadeia, o P é o preço das mercadorias e o L é o lucro predeterminado.

Com relação ao preço, o gestor tem pouco poder para trabalhar com esta variável, pois quem define o preço é o mercado. O lucro também já é preestabelecido, pois o negócio somente continuará atrativo se alcançar o retorno desejado pelos acionistas. Assim, resta ao gestor a variável custo para trabalhar. Entende-se como custo o "sacrifício financeiro com que a entidade arca para a obtenção de um produto qualquer ...."(MARTINS, 1992, p.23).

Traduzindo em números, se o mercado paga um preço de $\$ 50$ pela mercadoria e o lucro preestabelecido é de $\$ 10$, o custo máximo para a empresa continuar operando, sendo competitiva e atingindo o resultado desejado, é de $\$ 40$. Esta pressão nos resultados levou as empresas a 
repensarem seus modelos de gestão na busca por vantagens competitivas. Hoje, a empresa, dentro de uma nova visão de gestão, para ser competitiva, deve pensar não só em seus processos internos, mas em toda a sua cadeia de suprimentos.

Deve-se buscar sinergias internas e externas através da integração de processos de negócio ao longo da cadeia de suprimentos. As sinergias internas estão relacionadas ao desenvolvimento do processo operacional da empresa, isto é, das atividades executadas para a realização do objeto de produção. Na indústria agropecuária de frango, por exemplo, pode-se citar o desenvolvimento das matrizes, a incubação dos ovos, acompanhamento do desenvolvimento das aves para abate, o abate e distribuição de produtos acabados. As sinergias externas estão relacionadas ao relacionamento com os fornecedores e distribuidores, a fim de estruturar parcerias benéficas para ambos, contratante e contratado.

Da mesma forma, os indicadores de desempenho devem ser estabelecidos a fim de propiciarem um feedback dessa cadeia e verificar se as ações realizadas realmente estão se revertendo em vantagens competitivas. Kaplan e Norton (1997) afirmam que o que não é medido não é gerenciado. É através dos indicadores de desempenho que a empresa poderá verificar se os processos estão dentro dos padrões esperados, orçados ou se não estão atingindo o desempenho desejado para a consecução da estratégia. A agroindústria de frango, inserida nesse contexto, tem buscado ser pró-ativa na gestão de sua cadeia, visando ser competitiva não só nos processo internos, mas em todos as operações utilizadas para atendimento às necessidades dos clientes.

\section{A agroindústria de frango brasileira}

A gestão competente do processo de negócio agro-industrial tem colocado o Brasil entre os principais produtores e competidores do mercado mundial de frango. Ao verificar o desenvolvimento desta indústria, percebe-se uma história de sucesso. $O$ crescimento da agroindústria no Brasil é um exemplo de organização, desenvolvimento tecnológico e capacidade de gestão. Porém, há alguns fatores que despertam preocupação e que podem afetar a competitividade dessa indústria.

A produção brasileira de carne de frango, de acordo com os dados da ANUALPEC (SILVA, 2003, p.259), cresceu 124\% nos últimos dez anos, enquanto os Estados Unidos, o principal produtor mundial, apresentou um aumento de $45 \%$ no mesmo período. O Brasil ocupa a $3^{\mathrm{a}}$ posição mundial em termos de produção de frango, com 7.355.000 tons em 2002, ficando atrás somente de Estados Unidos e China, com 14.467.000 tons e 9.558.000 tons, de acordo com o Livestock and Poultry: world markets and trade (USDA, 2003). As exportações brasileiras no período entre 1992 e 2001 tiveram um aumento ainda mais surpreendente, crescendo 236\% (SABOYA, 2003, p.249). O Brasil ocupa a $2^{\mathrm{a}}$ posição em termos de volume exportado, com 1.588 .000 tons., perdendo apenas para os Estados Unidos, com 2.177.000 tons em 2002.

Apesar deste cenário vitorioso construído pela agroindústria nestas últimas décadas, há alguns fatores que despertam preocupação. Estes fatores diminuem o resultado da agroindústria de forma significativa, exercendo pressão com o aumento do custo dos insumos de produção, diminuição da receita e a pressão contínua para melhorar o retorno sobre investimento dos acionistas.

Com relação aos insumos, pode-se citar o exemplo de dois principais componentes, o farelo de soja e o milho. Esses dois insumos de grande peso na agroindústria têm seus preços balizados pela bolsa de Chicago, seguindo as tendências mundiais de preço, independente das safras nacionais. Eles representam em torno de $60 \%$ a $65 \%$ do custo do frango vivo, matéria-prima da agroindústria. De acordo com as tendências apontadas pelo World Agricultural Supply and Demand Estimates Report (USDA, 2003), em função dos estoques mundiais baixos e aumento do consumo, espera-se uma elevação desses dois insumos que, conseqüentemente, irão refletir no custo dos produtos no final da cadeia. 
Percebe-se novamente a importância da gestão de custos, pois é nos custos que a gestão da empresa concentrará esforços, identificando oportunidades de ganho ao longo da cadeia, a fim de alcançar os resultados preestabelecidos.

\section{A cadeia agro-industrial}

A figura 1 mostra a visão tradicional do macro processo agro-industrial de abate de frango. Percebe-se que o enfoque dado é nos processos internos. Os diversos valores despendidos neste processo têm o objetivo de viabilizar cada operação e atividade, isto é, desde os gastos relacionados a produzir ração, incubar ovos, criar matrizes e frangos de corte, abater, armazenar e distribuir os produtos acabados para os diferentes mercados de atuação. Nestes últimos anos, as empresas têm se voltado para os outros elos da cadeia em função de crescente valor percebido a eles atribuído e a pressão contínua de melhora nos resultados.

Figura 1 - Visão tradicional do macro processo agro-industrial de abate de frango

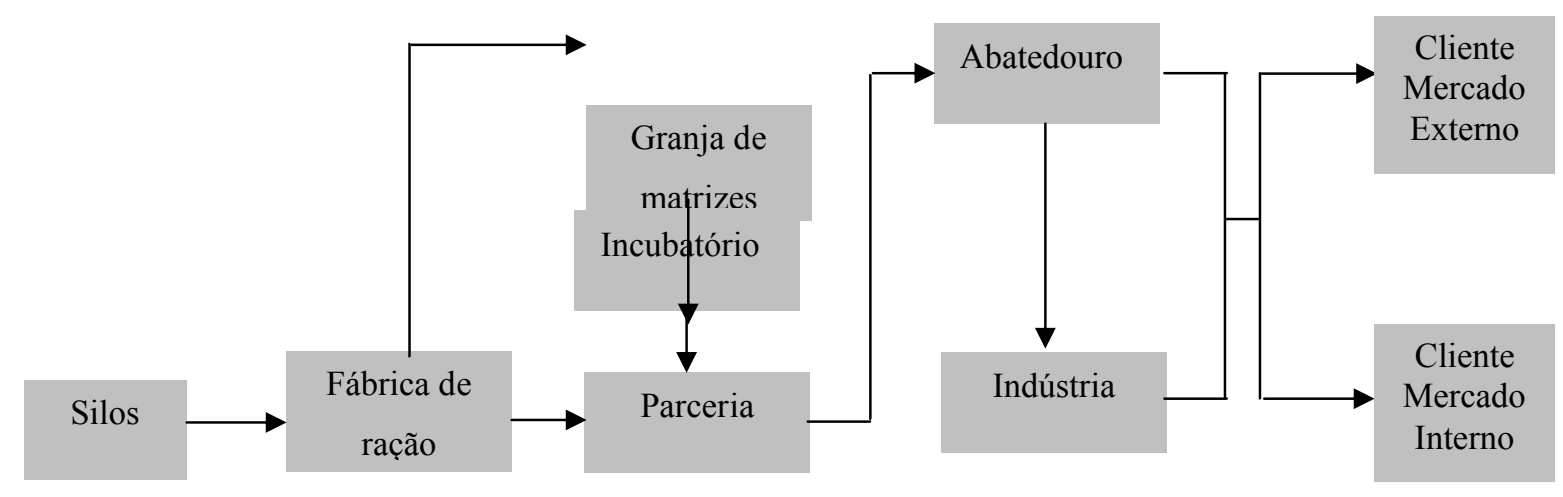

Os indicadores devem ser desenvolvidos de acordo com o conceito de gestão da cadeia de suprimentos, isto é, devem possibilitar a integração de processos de negócios chaves desde os usuários finais permeando fornecedores a fim de prover produtos, serviços e informações de valor agregado para clientes e acionistas (LAMBERT, 2000). A figura 2 mostra uma visão simplificada da cadeia de suprimentos.

Figura 2 - Cadeia de suprimentos

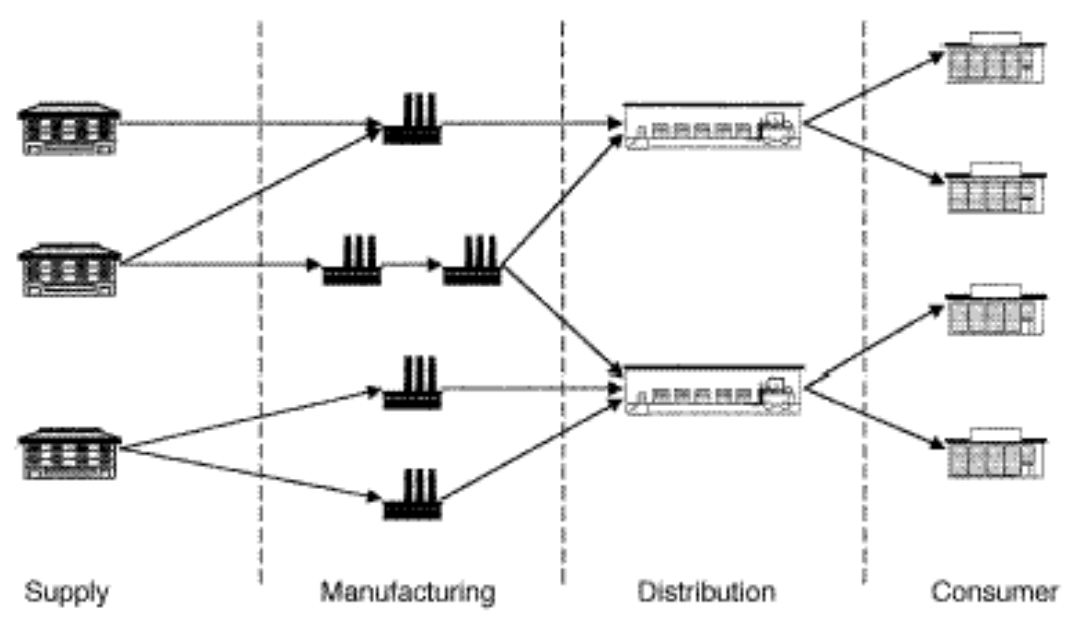

De acordo com o conceito mencionado, não basta ter somente processos internos eficientes, tais como produzir ração, abater, cortar e industrializar o produto. Deve-se pensar também nos 
outros elos dessa cadeia. Verifica-se que as atividades internas da empresa são apenas parte da cadeia, que se completa quando juntas às atividades de logística de suprimentos e distribuição, como mostrado na figura 3 , normalmente executada por terceiros.

Pela figura 3, percebe-se que a definição de indicadores de desempenho não se deve ater somente à avaliação dos aspectos internos da organização. Deve-se buscar o desenvolvimento de dois grupos distintos de indicadores, os quais devem interagir entre si, contemplando as atividades internas de produzir ração, abater, cortar e industrializar, assim como as externas de logística de suprimentos e distribuição.

Figura 3 - Macro processo agro-industrial de frango e seus elos entre processos internos

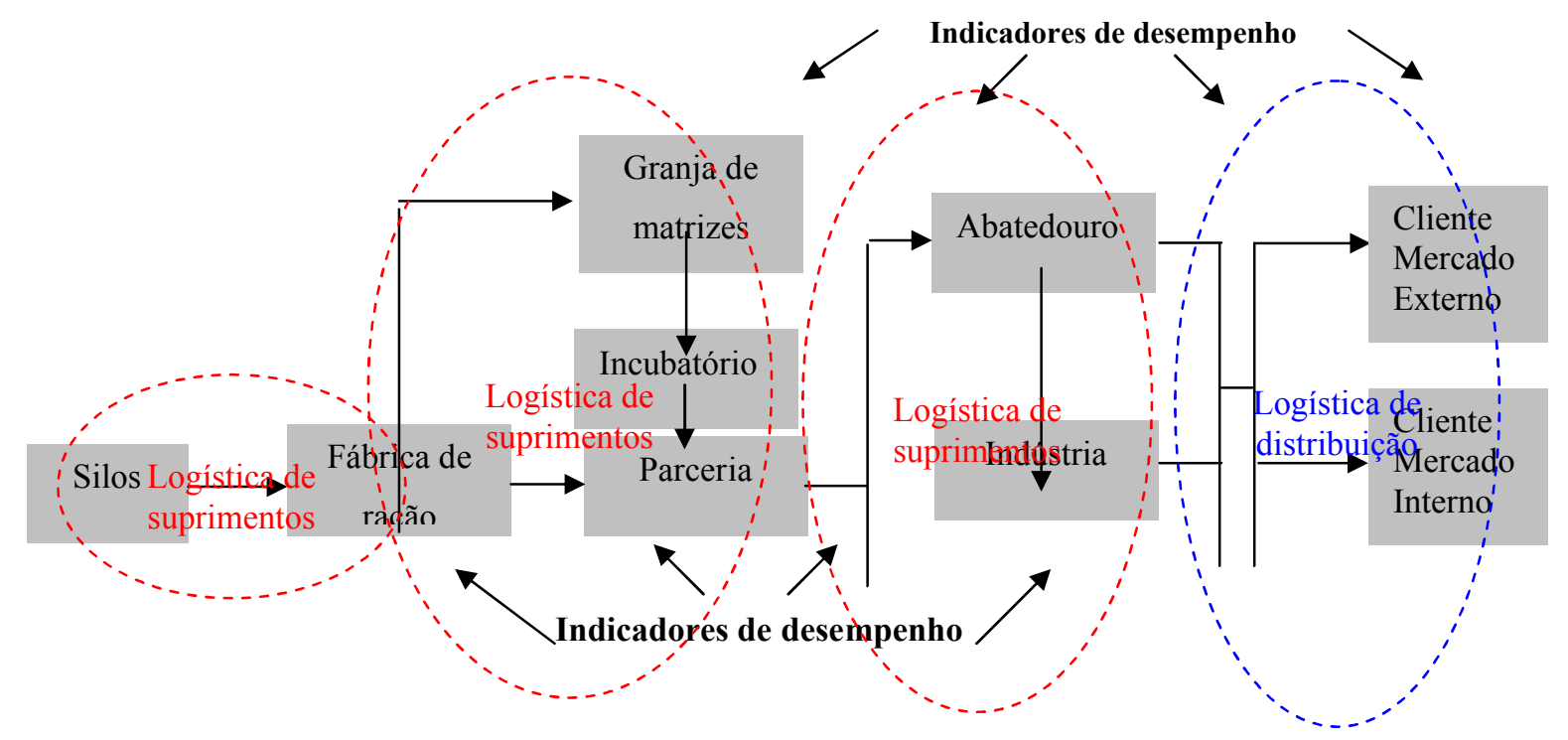

$\mathrm{O} 1^{\mathrm{o}}$ grupo de indicadores são os financeiros. Alguns exemplos encontrados na cadeia são: custo da hora trabalhada, custo da tonelada armazenada, custo da tonelada transportada por faixas de quilômetro, custo do quilo frango vivo, custo por tonelada produzida, custo por tonelada de distribuição via $C D^{\prime}$ 's, venda direta, cross docking ou container de produto acabado, valores alocados em estoques, além das tradicionais RONA, ROI, EBIT, EBTIDA para o negócio.

No $2^{\circ}$ grupo, têm-se as medidas não-financeiras. Alguns exemplos encontrados na cadeia de suprimentos são: nível de utilização dos silos, rotatividade da frota seja de graneleiro, frangueiro, pinteiro ou frigorificado, distância média dos parceiros, nível de utilização da capacidade de carga da frota, mortalidade, conversão alimentar, média de dias do frango no campo, UEPs por toneladas produzidas, número de pintos alojados, volume de vendas mercado interno e mercado externo, volume de produtos em estoque, etc.

O conceito de gestão da cadeia de suprimentos deve permear a estruturação e análise dos indicadores estabelecidos. Se os indicadores de desempenho forem desenvolvidos e analisados fora do conceito de gestão da cadeia de suprimentos podem trazer resultados bastante prejudiciais para todo o processo de negócio. Pode-se citar um exemplo de como uma decisão com o intuito de melhorar um indicador de desempenho em um dos elos da cadeia pode trazer reflexos indesejáveis nos processos subseqüentes. Em outras palavras, as ações de redução de custo em uma parte da cadeia não representam redução de custo para cadeia como um todo. O exemplo a seguir ilustra a necessidade de entender o conceito de cadeia de suprimentos e o processo de negócio da empresa.

\section{Impacto na cadeia}

Procura-se mostrar que medidas aparentemente benéficas a uma parte da cadeia são, na verdade, prejudiciais quando analisada toda cadeia utilizada pelo processo de negócio da empresa.

O que se descreve a seguir é o impacto de uma decisão relacionada ao lead time da viagem para apanhar frango no campo nos processos subseqüentes de abate e corte. A situação relatada 
mostra qual o impacto financeiro em algumas etapas da cadeia quando uma medida é tomada sem considerar toda a cadeia. O lead time da viagem é composto pelo tempo de carga, descarga e rodagem.

Suponha-se que o abate de frango diário seja de 150.000 aves e que a empresa terceirizada responsável pelo carregamento seja composta por 16 caminhões, tendo capacidade de 3.400 aves por viagem. Assim, o número de viagens necessárias para atender a demanda do abatedouro é de aproximadamente 44 viagens (150.000 aves / 3.400 aves por viagem). Para uma frota de 16 caminhões, isto significa que cada caminhão fará 2,76 viagens no dia (44 viagens / 16 caminhões). O período de trabalho diário é de 10 horas. Então, o lead time da viagem será em média de 3,63 horas (10 horas / 2,76 viagens).

Diversas ações que a princípio parecem reduzir custo podem na verdade produzir um efeito contrário quando analisados os impactos na cadeia. Caso haja ações no sentido de reduzir equipes de apanhe de frango, diminuir a estrutura de descarga de caminhão ou adotar uma frota de caminhões pouco cuidada, isto poderá afetar diretamente o lead time da viagem. A princípio, pode haver uma redução de custo nas contas vinculadas a estes processos. Porém, deve-se levar em consideração também o impacto na cadeia através de um provável aumento do lead time da viagem.

Caso, em função destas ações, o lead time da viagem seja aumentado em $10 \%$, passando de 3,63 horas para 3,99 horas, ocorrerá uma diminuição do número de viagens dia por caminhão. Onde antes cada caminhão tinha em média 2,76 viagens por dia, em função destas mudanças, o número médio de viagens passará para 2,51 viagens por dia (10 horas de trabalho dia / 3,99 horas por viagens). A cada viagem, são transportadas 3.400 aves. Logo, cada caminhão conseguirá abastecer por dia o abatedouro com 8.523 aves. Para atender a necessidade diária do abatedouro, serão necessários 17,60 caminhões (150.000 aves / 8.523 aves dia por caminhões).

Ao comparar a situação antes do aumento do lead time da viagem com a descrita no parágrafo anterior, percebe-se necessidade de aumento de 1,60 caminhões (17,60 caminhões - 16 caminhões), a fim de atender a mesma necessidade de abate. $O$ aumento da necessidade de caminhões traz perda para a empresa contratada, assim como para empresa contrantante. $\mathrm{O}$ impacto financeiro negativo para a empresa contratada é decorrente da diminuição do giro e, para a empresa, pode ser decorrente do aumento da quebra de espera, mortalidade de animais no transporte e conseqüente perda da margem de contribuição proveniente da venda destes produtos.

No caso da frota contratada para caminhões de frango, por exemplo, o pagamento mensal gira em torno de R\$ 7.000,00 no mês por caminhão. Em função da diminuição do giro da frota decorrente do aumento do lead time da viagem, os caminhões fazem menos viagens. Conseqüentemente, há necessidade de 1,60 caminhões a mais por dia. A perda para a empresa contratada se fossem mantidos os 16 caminhões será de $\mathrm{R} \$ 11.200,00$ no mês $(\mathrm{R} \$ 7.000,00$ X 1,60 caminhões). Para a empresa, o valor total a ser pago não se altera, pois o pagamento é por tonelada. Porém, para o terceiro, estes $\mathrm{R} \$ 11.200,00$ poderiam ser revertidos em melhora de equipamentos, manutenção dos veículos e até mesmo na manutenção das tarifas de frete no curto-prazo.

Para a empresa, pode haver perdas em termos de quebra de espera, mortalidade e margem de contribuição. A quebra de espera significa perda de peso do frango e mortalidade é o número de frangos mortos antes de chegar no abatedouro. $\mathrm{O}$ aumento destes dois itens são proveniente de um maior tempo que os frangos ficam nos caminhões.

Se o abatedouro em questão trabalha 22 dias úteis no final do mês, o total abatido será de 3.300 .000 aves (150.000 aves dia X 22 dias). Se as aves têm um peso médio de 2,350 kg, os quilos totais transportados serão de $7.755 .000 \mathrm{~kg}(3.300 .000$ aves X 2,350 kg). Se houver um aumento de $0,03 \%$ na quebra de espera e mortalidade, percentual facilmente alcançado em função do aumento do lead time da viagem, ter-se-á os seguintes impactos financeiros. Com $0,03 \%$ aplicado aos $7.755 .000 \mathrm{~kg}$, significa que $2.326,50 \mathrm{~kg}$ deixarão de ser abatidos. Supondo que o custo do quilo do frango vivo seja de $\mathrm{R} \$ 1,60$ por $\mathrm{kg}$, o valor perdido será de $\mathrm{R} \$ 3.722,40$ por mês $(2.623,50 \mathrm{~kg} X \mathrm{R} \$$ $1,60 \mathrm{~kg})$.

Os $2.326,50 \mathrm{~kg}$ de frango vivo transformados em peso carcaça resultarão em $1.698 \mathrm{~kg}$ $(2.326,50 \mathrm{~kg}$ X $0,73 \%$ rendimento da carcaça). A perda de margem de contribuição por não vender 
estes quilos de carcaça pode chegar a $\mathrm{R} \$ 934,00$ por mês $(1.698 \mathrm{~kg} \mathrm{X} \mathrm{R} \$ 0,006$ por $\mathrm{kg}$ de margem de contribuição).

A perda, se analisada no mês, pode parecer pouca, tanto para o terceiro quanto para a empresa, sendo, respectivamente, $\mathrm{R} \$ 11.200,00$ e $\mathrm{R} \$ 4.656,40$ ( $\mathrm{R} \$ 3.722,40+\mathrm{R} \$ 934,00)$ ). Porém, no ano, o terceiro perde $\mathrm{R} \$ 134.400,00$ e a empresa, $\mathrm{R} \$ 55.877,00$. Se esta empresa tem outros 8 abatedouros e a mesma medida venha a acarretar as mesmas conseqüências financeiras nas outras instalações, o valor ano da empresa poderá chegar a $\mathrm{R} \$ 447.000,00$. Este valor é bastante significativo, principalmente neste ramo de indústria, que opera com margens operacionais de ganho bastante reduzidas.

De forma resumida, a perda da cadeia por uma ação no intuito de reduzir custo e melhorar um indicador de desempenho financeiro em uma das etapas do processo foi de $\mathrm{R} \$ 15.856,40$, sendo $\mathrm{R} \$ 11.200,00$ provenientes dos prestadores de serviço mais $\mathrm{R} \$ 4.656,40$ da empresa. A pergunta que surge é: será que a redução de custo obtida nesta ação supera as perdas descritas nos outros elos da cadeia? Provavelmente não, pois os valores da estrutura de carga e descarga são pequenos, se comparados às outras etapas envolvidas no processo aqui descrito.

\section{Considerações finais}

O não entendimento do processo de negócio assim como a instituição de indicadores de desempenhos separada do conceito de gestão da cadeia de suprimentos pode levar a resultados como o descrito no exemplo.

O raciocínio inverso sobre todo o caso descrito também é verdadeiro, isto é, um investimento na melhora do lead time da viagem provavelmente trará os resultados descritos anteriormente em forma de ganhos. Ganhos para todos envolvidos na cadeia de suprimentos agroindustrial de abate de frango, desde fornecedores, empresa e cliente final.

Ganhos insignificantes quando vistos isoladamente podem parecer que não valha o esforço, porém quando se pensa em larga escala, como no caso das grandes indústrias de abate de frango, o resultado é bastante representativo. Analisada de forma isolada a economia de $\mathrm{R} \$ 0,02$ é insignificante, porém no contexto de escala, tem-se outra situação. Por exemplo, se houver uma redução de $\mathrm{R} \$ 0,02$ no custo por quilo do frango vivo, matéria-prima para indústria de aves, o ganho é enorme. Basta pensar que nas grandes agroindústrias de frango do país, onde hoje são abatidas em torno de 19.000 .000 de aves mês, a um peso médio de $2,400 \mathrm{~kg}$. A economia gerada, fazendo os cálculos será de R\$912.000,00 por mês $(19.000 .000 \mathrm{Kg}$ X 2,400Kg X R\$0,02/Kg).

O aprimoramento dos modelos de indicadores de desempenho poderá assegurar a gestão eficiente do negócio agro-industrial em um mercado mais competitivo e com margens operacionais cada vez mais reduzidas, onde economias de centavos em um processo podem representar a diferença entre lucro e prejuízo no fechamento das contas. Este aprimoramento significa escolha de indicadores relevantes e confiáveis que propiciem a tomada de decisão a fim de obter ganhos na cadeia de suprimentos.

De acordo com Beamon (1999, p.289), há ainda poucas medidas de desempenho para a cadeia de suprimentos, a situação é pior quando se aborda processos de negócios específicos como no caso da agroindústria de frango. Há um vasto campo de pesquisa a ser explorado no intuito de contribuir para melhora dos indicadores para este ramo específico e tão importante da indústria nacional.

\section{Abstract}

The article shows why the market environment has been leading the industries to search new ways to keep competitivies. In theses last years, the brazilian poultry business industry has realized that there are concerning factores despite the excellent global performance. The industry is trying to find sinergies along its supply chain and keeping its high standard of financial performance as have been reached years before. The performance measures should play a important role in this search but the proper choice of them is a challenge. Some examples show how much damage can be a decision 
taken without understand all reflects in the suply chain.

Key words: performance measures; decision; supply chain.

\section{Referências}

BEAMON, Benita M. Measuring Supply Chain Performance. International Journal of Operational and Production Management, v. 19, n. 3, 1999.

BORNIA, Antonio C. Análise Gerencial de Custos: aplicação em empresas modernas. Porto Alegre: Bookman, 2002.

BOWERSOX, D. J.; CLOSS D. J. Logistical Management: the integrated supply chain process. New York: McGrawHill. 3. ed. 1996.

FISCHMANN, A. A.; ZILBER, M. A. (1999) Utilização de indicadores de desempenho como instrumento de suporte à gestão estratégica. In: ENANPAD, 23., Foz do Iguaçu. Anais... Foz do Iguaçu.

KAPLAN, R. S.; NORTON, D. P. A estratégia em ação: balanced scorecard. 4. ed. Rio de Janeiro: Campus, 1997.

LAMBERT, Douglas M., COOPER, Martha C.. Issue in Supply Chain Management. Industrial Marketing Management, v. 29, n. 1, 2000.

LAMBERT, Douglas M.; POHLEN, Terrance L. Supply Chain Metrics. The International Journal of logistics Management, v. 12, n. 1, 2001.

MARTINS, Eliseu. Contabilidade de Custos. 4. ed. São Paulo: Atlas. 1992.

OTLEY, David. Issues in Management Accounting. 2. ed. London: Prentice Hall, 1995.

SABOYA, Leopoldo V. A dinâmica recente da produção brasileira de aves e suínos. Anuário da Pecuária Brasileira. São Paulo, 2003.

SILVA, Deives F. Chance de ganhar mais competitividade no frango. Anuário da Pecuária Brasileira. São Paulo, 2003.

United State Departament of Agriculture - USDA. Livestock and Poultry: world markets and trade. Washington: Circular Series, 2003.

United State Departament of Agriculture - USDA. World Agricultural Supply and Demand Estimates Report. Washington: Circular Series, 2003. 